\title{
Case Study on Pulse DC Electric Field for Weakening Interfacial Film of Aging Oil
}

\author{
Yun-Feng SUN ${ }^{1,2, a}$, Yang LIU ${ }^{1, b}$, Lei ZHANG ${ }^{1, c}$, Meng-Meng XU ${ }^{1, d}$ \\ ${ }^{1}$ Key Laboratory for Enhanced Oil \& Gas Recovery of the Ministry of Education, Northeast Petroleum \\ University, Daqing, Heilongjiang, 163318, PR China \\ ${ }^{2}$ Gas Production Company, Daqing Oilfield Company Limited, Daqing, Heilongjiang, 163002, PR \\ China \\ alyq04598848@sina.com, bnepuwzh@163.com, c1907141877@qq.com, d491789788@qq.com
}

Keywords: Interfacial tension, Electrochemical demulsification, Pulse DC electric field, Coalescence material, Energy supply

\begin{abstract}
Coalescence effect of the surface disposal devices is greatly impacted by the large amount of aging oil because of its complicated interfacial properties, which heavily affects oil production. The typical aging oil properties are evaluated, interfacial properties and the causes of formation are discussed in the paper. It is not efficient enough for aging oil to be disposed only with the methods of the chemical or electric-field, even though the later one has many advantages in breaking oil-water interfacial film. The water content in oil, oil content in water and the oil-water interface properties after separated can meet the industrial standard by the integration disposal of the two methods. But the pulse DC power supply must be selected in the electric-field formation so that the instantaneous high power electric pulse can be created without electrodispersion, which can easily break the oil-water interfacial film and prevent current leakage. Besides, the aging oil disposal process is designed and the operating parameters are also optimized in the paper.
\end{abstract}

\section{Introduction}

Dehydration is a significant link of crude oil treatment system. With the development of oilfield entering high water cut stage and application of enhanced oil recovery technologies, more and more aging oil are produced during crude oil production and treatment process [1, 2]. The aging oil is characterized by strengthened emulsification and thick oil-water interfacial film, which is challenge for aging oil dehydration. If the water cut of dehydrated oil is higher than allowable value, the damage is enormously. Such as the storage, transportation and refining of oil are more difficulty, and the equipments can be corroded and the mechanical admixtures will deposit at pipe wall [3]. Therefore, appropriate dehydration process is the premise for ensuring the quality of dehydrated aging oil.

Crude oil dehydration includes free water and emulsifying water. Usually the dehydration process of free water is transporting produced liquid to settling tank and achieved oil and water separation by gravity settling [4]. But the emulsifying water is difficult to be separated. In the world, the main dehydration technologies of emulsifying water are ultrasonic method, thermo-chemical and electric dehydration, recently [5,6]. The electric dehydration technology is widely used in the crude oil treatment system because of high efficiency and fast speed. And according to kinds of electric fields, the dehydration technologies mainly include alternating current, direct current and pulse power supply.

\section{Properties of Aging Oil}

In oilfield, the aging oil, such as bailing oil, landing oil and sump oil in settling tank, is stored up over a long time, and contains a large number of mechanical admixtures, sulfate reducing bacteria (SRB) and sulfides, which is difficult to be dealt with. Under aeration conditions, the thickness and intensity of oil-water interfacial film of emulsion will be strengthened because of the effects of air, temperature, mechanical admixtures and various emulsifiers, which will accelerate the aging oil form. 
The sulfate in produced liquid can be reduced to hydrogen sulphide $\left(\mathrm{H}_{2} \mathrm{~S}\right)$ by SRB. The $\mathrm{H}_{2} \mathrm{~S}$ will take chemical reaction with transporting and treatment equipments, so lots of FeS is formed. The FeS will deposit on the oil-water interfacial film to form a tight rigid film, which can prevent water-drops coalescence and stabilize oil-water transition layer. In addition, due to electrification of particles in the aging oil, the particles will make directional movement between the top and bottom electrode plates under external electric field. This will make the current going up suddenly and affect the safe running of electrical dehydrator. Moreover, the disposal difficulty of oily water will be greater and the quality of treated water will be deteriorated if the aging oil enters the water treatment process.

Due to the stronger stability of aging oil emulsion, conventional dehydration methods can not break emulsion and accomplish dehydration. In order to select an economical and effective method for aging oil dehydration, the properties of aging oil are studied by indoor experiments. This paper takes aging oils from Daqing Oilfield as case and analyses the properties of various aging oils. The experimental results are shown in Table 1.

Table 1 Experimental Results of Aging Oil Properties

\begin{tabular}{llllll}
\hline Oil Kind & $\begin{array}{l}\text { Asphaltene } \\
\text { Content [\%] }\end{array}$ & $\begin{array}{l}\text { Mechanical } \\
\text { Admixture } \\
\text { Content[\%] }\end{array}$ & $\begin{array}{l}\text { Fe Content } \\
{[\%]}\end{array}$ & $\begin{array}{l}\text { SRB Amount } \\
{[\text { ind/mL] }}\end{array}$ & $\begin{array}{l}\text { Sulfide } \\
\text { Content } \\
{[\mathrm{mg} / \mathrm{L}]}\end{array}$ \\
\hline Bailing Oil & 26.77 & 1.27 & 0.18 & 2,500 & 8.35 \\
\hline Landing Oil & 24.10 & 58.50 & 1.75 & 1,300 & 6.10 \\
\hline Common Oil & 23.95 & 0.88 & 0.13 & 60 & 1.82 \\
\hline
\end{tabular}

\section{Application of Pulse Power Supply in Aging Oil Dehydration}

\section{Dehydration Mechanism.}

In alternating current field or direct current field, the water drops in emulsion will make dipole coalescence, electrophoretic coalescence and oscillating coalescence due to the electric field force $[7,8]$. Then the water drops will be enlarged and settling rate will be accelerated, and oil-water separation will be accomplished finally. The pulse power supply dehydration technology is established base on alternating and direct current technology. It can make high-voltage electric field without electrodispersion and the voltage is higher than alternating and direct fields. The instantaneous high power electric pulse created by pulse power supply can break the oil-water interfacial film easily. And the opportunities of water drops coalescence will be increased in the pulse electric field, so the dehydration rate will be accelerated. In addition, according to the properties and amount of oil, the pulse width will be automaticly adjusted to control the polarization time of hydrone. It can prevent current leakage caused by the regular spread of polarized hydrone [9].

\section{Dehydration Equipment.}

The pulse power supply electric dehydrator is composed of pulse power supply equipment and electric dehydrator. The electric dehydrator is horizontal type and the size is $\Phi 4,000 \times 16,000 \mathrm{~mm}$. The pulse power supply equipment includes a high frequency pulse power supply producer and a high frequency pulse vertoro $[10,11]$. The high frequency pulse power supply producer is composed of three-phase silicon rectifier, variable frequency main circuit, driving circuit, pulse width modulating circuit and pulse booster circuit. And the high frequency pulse vertoro is composed of transformer and rectifier. The high voltage and low voltage windings of transformer are two separate coils. The rectifier is composed of two reverse parallel diodes. The output power of pulse power supply equipment is $0 \sim 50 \mathrm{kVA}$ and the wave shape is square wave.

\section{Main Production Parameters.}

Pulse frequency, electric field strength, dehydration time and dehydration temperature are the main parameters for dehydration effect of pulse power supply electric dehydrator. Through the parameter 
optimization experiments, determining the optimal running parameters is significant for high-efficient dehydration and energy saving.

\section{Pulse Frequency.}

The resonance phenomenon will happen when the pulse frequency is equal to or close to the intrinsic oscillation frequency of emulsion droplets. At this point, the amplitude of the droplets is the greatest and the stability is the worst. The oil-water film will be broken by mechanical vibration and adjacent water drops will coalesce to form new drops with bigger diameter, which will increase the settling rate and make it easy to achieve oil-water separation. According to the experimental results, $2 \mathrm{kHz}$ is the optimal frequency for aging oil dehydration in Daqing Oilfield.

\section{Electric Field Strength.}

The coalescence force between water drops will increase with the increase of electric field strength. But the increasing tendency of coalescence force is not linear. When the electric field strength reaches a certain extent, electrodispersion, which is bad for dehydration, will happen. So it is necessary to determine optimal electric field strength, which not only ensures enough coalescence force but also avoids electrodispersion happening. According to the experimental results, $2,000 \mathrm{~V} / \mathrm{cm}$ is the optimal electric field strength for aging oil dehydration in Daqing Oilfield.

\section{Dehydration Time.}

The dehydration rate will increase with the increase of dehydration time. But when water cut of dehydrated oil reaches a certain value, it no longer changes with the increase of time. In order to ensure the quality of dehydrated oil and save power, optimal dehydration time should be determined. According to the experimental results, 100 minutes is the optimal dehydration time for aging oil dehydration in Daqing Oilfield.

\section{Dehydration Temperature.}

The viscosity of emulsion will decrease with the increase of temperature, which will intensify the thermal motion of droplets and increase the opportunities of colliding and coalescence. But the heating also brings some disadvantages, such as light component volatilizing, investment increase and power waste. So it is significant to determine optimal dehydration temperature. According to the experimental results, $60^{\circ} \mathrm{C}$ is the optimal dehydration temperature for aging oil dehydration in Daqing Oilfield.

\section{Establishment and Optimal Selection of Aging Oil Dehydration Process}

\section{\#1 Scheme.}

As shown in Fig. 1, the overall process of dehydrating station adopts two-stage dehydration technology, the first is free water dehydrator and the second is pulse power supply electric dehydrator. The process can be applied in common oil dehydration and aging oil single dehydration. Due to the lots of impurities in aging oil, which is easy to attach at the electrodes in electric dehydrator, the stability of electric field is reduced. So the electrodes are hanged vertically. When the process is used for common oil dehydration, the treatment flowrate should be $60 \mathrm{~m}^{3} /$ hour. And the water cut of dehydrated oil is lower than $0.3 \%$ under the optimal running parameters. When the process is used for aging oil dehydration, the treatment flowrate should be $30 \mathrm{~m}^{3} /$ hour. And the water cut of dehydrated aging oil is lower than $0.3 \%$ under the optimal running parameters. 


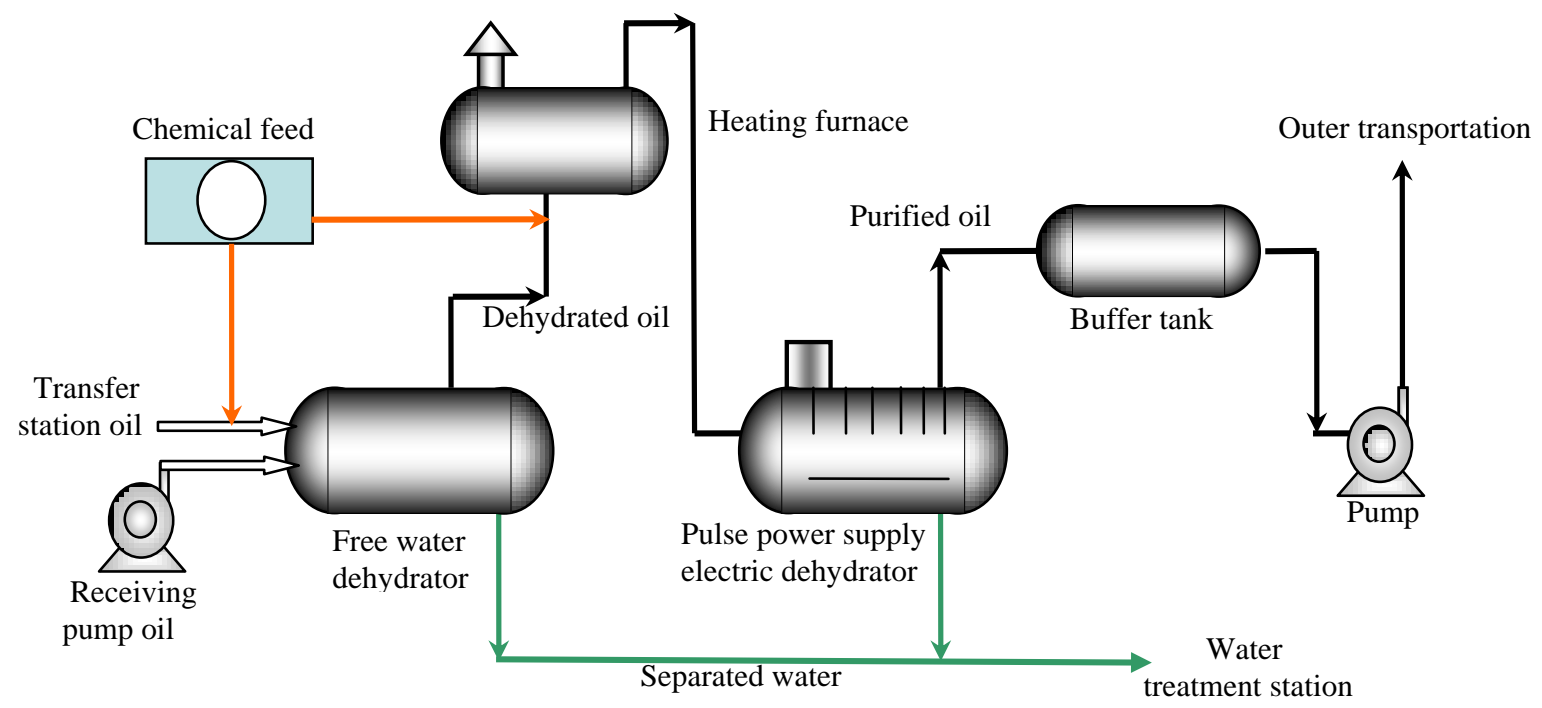

Fig. 1. Sketch Map of Pulse Power Supply Dehydration Process

The dehydration technological process is following: The free water in liquid from transfer station or receiving pump is dehydrated by free water dehydrator. When the water cut of dehydrated oil below $30 \%$, the oil will be transported into heating furnace. And the oil will flow into pulse power supply electric dehydrator to dehydrate emulsifying water when oil temperature reaches $60^{\circ} \mathrm{C}$. Then the purified oil will enter into buffer tank to wait for transporting away. The separated water dehydrated by free water dehydrator and pulse power supply electric dehydrator will be transported to water treatment station.

\section{\#2 Scheme.}

As shown in Fig. 2, the overall process of dehydrating station adopts two-stage dehydration technology, the first is free water dehydrator and the second is pulse power supply electric dehydrator. Also, the electrodes are hanged vertically. Compared with \#1 scheme, the difference is that an ultrasonic dehydration plant is installed ahead of the pulse power supply electric dehydrator. When the process is used for aging oil dehydration, the treatment flowrate should be $50 \mathrm{~m}^{3} /$ hour. And the water cut of dehydrated aging oil is lower than $0.3 \%$ under the optimal running parameters.

The dehydration technological process is following: The free water in liquid from transfer station or receiving pump is dehydrated by free water dehydrator. When the water cut of dehydrated oil below $30 \%$, the oil will be transported into heating furnace. And the oil will be re-dehydrated by ultrasonic dehydration plant when oil temperature reaches $60^{\circ} \mathrm{C}$. Then the re-dehydrated oil will flow into pulse power supply electric dehydrator. The purified oil will enter into buffer tank to wait for transporting away. The separated water dehydrated by free water dehydrator and pulse power supply electric dehydrator will be transported to water treatment station. 


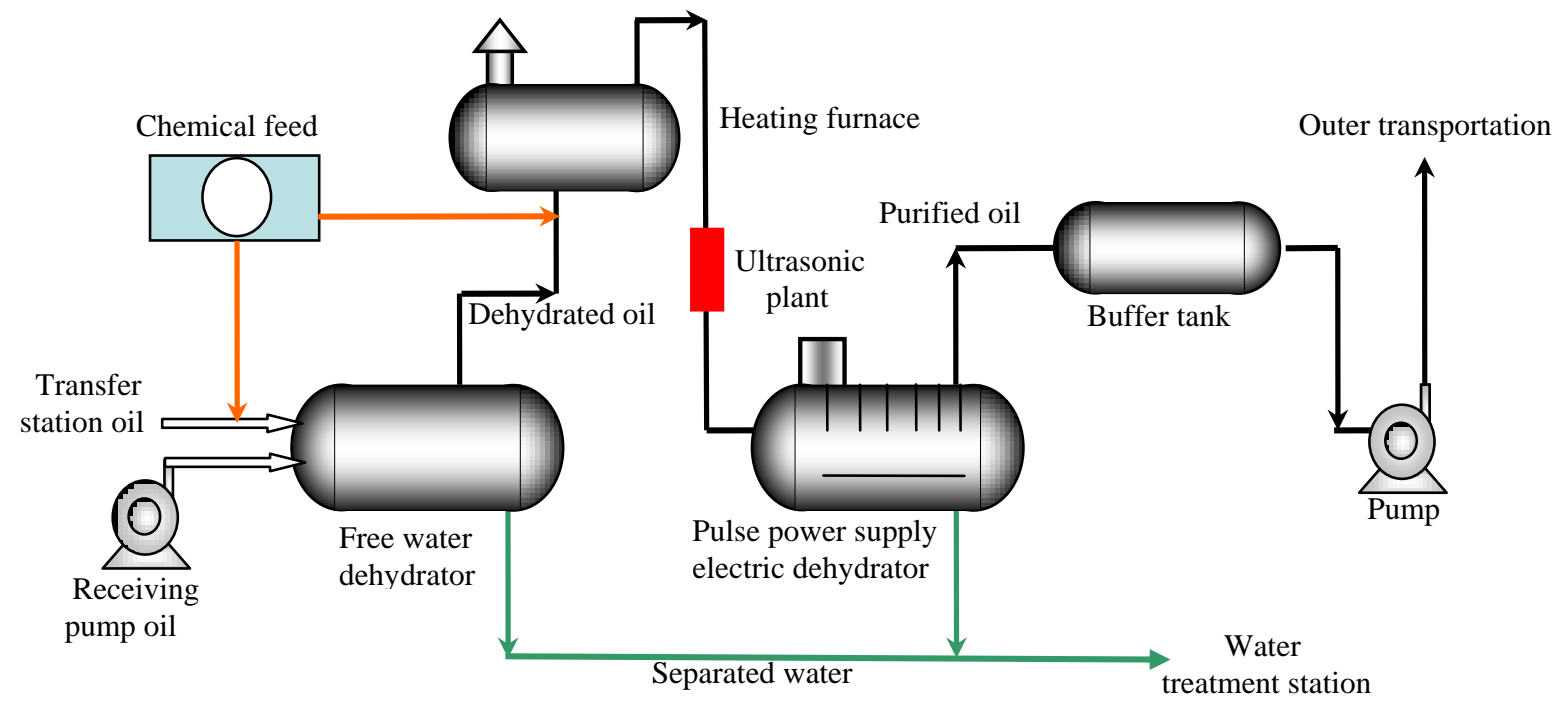

Fig. 2. Sketch Map of Ultrasonic Pre-dehydration Process

\section{\#3 Scheme.}

As shown in Fig. 3, the overall process of dehydrating station adopts three-stage dehydration technology, the first is free water dehydrator, the second is thermo-chemical dehydrator and the third is pulse power supply electric dehydrator. Also, the electrodes are hanged vertically. When the process is used for aging oil dehydration, the treatment flowrate should be $50 \mathrm{~m}^{3} /$ hour. And the water cut of dehydrated aging oil is lower than $0.3 \%$ under the optimal running parameters.

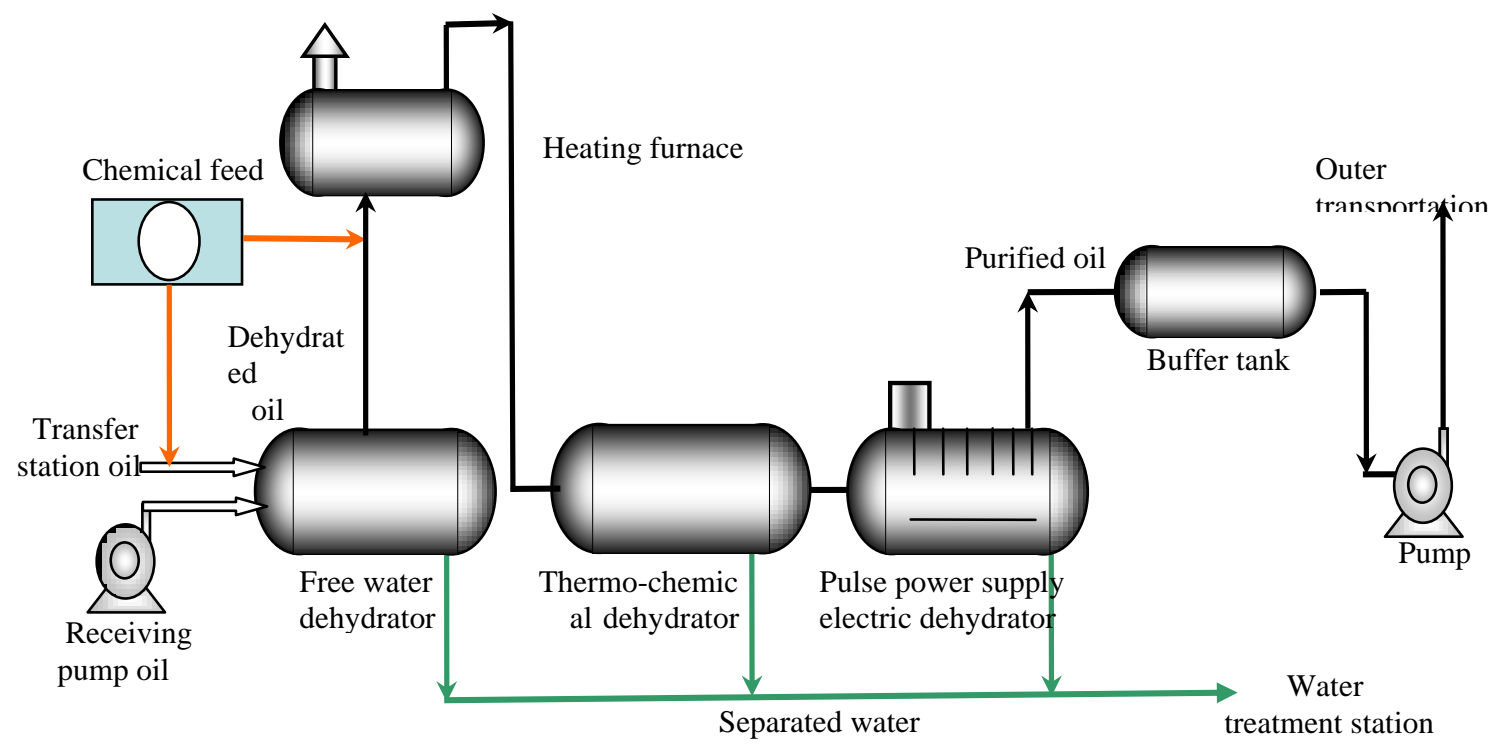

Fig. 3. Sketch Map of Three-Stage Dehydration Technology Process

The dehydration technological process is following: The free water in liquid from transfer station or receiving pump is dehydrated by free water dehydrator. When the water cut of dehydrated oil below $30 \%$, the oil will be transported into heating furnace. And the oil will enter thermo-chemical dehydrator when oil temperature reaches $70^{\circ} \mathrm{C}$. Then the re-dehydrated oil will flow into pulse power supply electric dehydrator. The purified oil will enter into buffer tank to wait for transporting away. The separated water dehydrated by free water dehydrator, thermo-chemical dehydrator and pulse power supply electric dehydrator will be transported to water treatment station. 


\section{Comparison and Optimal Selection of Dehydration Process}

The optimal dehydration process is selected by comprehensive comparing the dehydration effect, construction investment, heat consumption and power consumption of the three processes above. And Table 2 shows the results.

Table 2 Comparison of the Dehydration Process

\begin{tabular}{llll}
\hline $\begin{array}{l}\text { Dehydration } \\
\text { Scheme }\end{array}$ & Construction Investment & $\begin{array}{l}\text { Heat Consumption } \\
{[\mathrm{kJ} / \mathrm{tonne}]}\end{array}$ & $\begin{array}{l}\text { Power Consumption } \\
{[\mathrm{kW} \cdot \mathrm{h} / \text { year] }}\end{array}$ \\
\hline$\# 1$ & - & 73,500 & 175,200 \\
\hline$\# 2$ & $\begin{array}{l}\text { An ultrasonic dehydration plant } \\
\text { more than \#1 }\end{array}$ & 73,500 & 219,000 \\
\hline$\# 3$ & $\begin{array}{l}\text { A thermo-chemical dehydrator } \\
\text { more than \#1 }\end{array}$ & 110,200 & 175,200 \\
\hline
\end{tabular}

It is known that three processes all can make water cut of dehydrated aging oil below $0.3 \%$. But the construction investment of \#1 scheme is the least. The heat consumption of \#1 is $36,700 \mathrm{~kJ} /$ tonne less than \#3, which is equal to saving natural gas with $1.15 \mathrm{~m}^{3}$ when one tonne oil is dehydrated. And the power consumption of \#1 is also the least. So the \#1 pulse power supply dehydration process is the optimal for aging oil dehydration.

\section{Conclusions}

There are much SRB, sulfides and mechanical admixtures in aging oil, and the common methods are not suitable for its dehydration. The instantaneous high power electric pulse created by pulse power supply can break the oil-water interfacial film easily and dehydrate aging oil efficiently. The optimal running parameters, such as pulse frequency, electric field strength, dehydration time and dehydration temperature, are determined by indoor experiments. According to the field conditions, three aging oil dehydration processes are established. And the \#1 pulse power supply dehydration process is selected by comprehensive comparison.

\section{Acknowledgements}

This work was financially supported by the State Key Program of National Natural Science Foundation of China (Grant No. 51534004) and the University Nursing Program for Young Scholars with Creative Talents in Heilongjiang Province (Grant No. UNPYSCT-2015074).

\section{References}

[1] Z. Wang, X. Le, Y. Feng and Z. Hu, Dehydration of aging oil by an electrochemical method, Chemistry and Technology of Fuels and Oils, 50 (2014) 262-268.

[2] R. Zhang, Y-S. Wu and P. Fakcharoenphol, Non-darcy displacement in linear composite and radial aquifer during $\mathrm{CO}_{2}$ sequestration. International Journal of Oil, Gas and Coal Technology, $7(2014)$ 244-262.

[3] Z. Wang, R. Pang, X. Le, Z. Peng, Z. Hu and X. Wang, Survey on injection-production status and optimized surface process of ASP flooding in industrial pilot area, Journal of Petroleum Science and Engineering, 111(2013) 178-183.

[4] L.M. Powers, Analysis of gravity separation in free-water knockouts, SPE Production Engineering, 5 (1990) 52-58.

[5] W.H. Thomason, P. Singh and D.J. Blumer, Advanced electrostatic technologies for dehydration of heavy oils, SPE 97786, presented at the SPE International Thermal Operations and Heavy Oil Symposium, Calgary, Alberta, Canada, 2005. 
[6] C. Dalmazzone, C. Noïk and P. Glénat, Development of a methodology for the optimization of dehydration of extraheavy-oil emulsions, SPE Journal, 15 (2010) 726-736.

[7] S.E. John and G. Mojtaba, Electrostatic enhancement of coalescence of water droplets in oil: A review of the technology, Chemical Engineering Journal, 85 (2002) 357-368.

[8] R. Zhang, X. Yin, P.H. Winterfeld and Y-S. Wu, A fully coupled thermal-hydrological-mechanical-chemical model for $\mathrm{CO}_{2}$ geological sequestration, Journal of Natural Gas Science and Engineering, 28(2016) 280-304.

[9] O.M. Midtgard, Electrostatic field theory and circuit analysis in the design of coalescers with pulsed dc voltage, Chemical Engineering Journal, 151 (2009) 168-175.

[10] Y.J. Li and S.Sun, New Technique Application of Aging Oil, Drilling \& Production Technology, 31 (2008) 139-141.

[11] Y. Liu, Z. Wang, X. Zhuge and S. Wang, Study on emulsification behavior and optimized separation technology of high concentration polymer flooding produced liquid in Daqing Oilfield, Presented at the SPE Middle East Oil \& Gas Show and Conference, Manama, Bahrain, 8-11 March, 2015, SPE-172768-MS. 